\title{
Autonomía e imperativo del decir en la web interactiva. Una reflexión sobre el hacer archivo en redes sociales a partir del contexto argentino actual ${ }^{*}$
}

\author{
Diego Germán Vigna* \\ Recibido: 2017-05-27 Enviado a pares: 2017-05-30 \\ Aprobado por pares: 2017-06-18 Aceptado: 2017-07-05 \\ DOI: 10.22395/angr.v16n31a4
}

\begin{abstract}
Resumen
Desde hace una década y media, las formas de hacer archivo y de intervención autoral en formatos web han invadido distintas esferas de acción de los sujetos, y han propiciado conductas de construcción identitaria y cultural. Formas de inscripción y de organización documental que hasta hace poco parecían restringidas al estudio sobre archivos institucionales, archivos de escritores u otras formas de preservación del patrimonio cultural, hoy modelan prácticas cotidianas de sujetos que se involucran con procesos relacionales mediados por tecnologías. En el marco de esta problemática, nuestro objetivo es reflexionar acerca de las formas de hacer archivo en el contexto de las redes sociales virtuales, a las que consideramos centrales para comprender la dinámica de intervención de sujetos y grupos en el ambiente digital interactivo.
\end{abstract}

La reflexión se sustenta en un análisis documental de las publicaciones e intervenciones de usuarios en la red social más utilizada en Argentina, Facebook, tomando como referencia empírica la última campaña presidencial de 2015. El análisis se estructura al considerar cada publicación o post como una unidad de contenido, siguiendo el principio de modularidad digital. Tomamos la campaña presidencial de 2015 en Argentina porque, en su desarrollo, el componente interactivo fue clave a partir de una premisa de acción fundamental surgida del análisis, que denominamos imperativo del decir. Esta noción, en el marco de una gramática de publicación y archivación específica, es central para comprender estrategias de captación de votos concebidas desde la supuesta autonomización de los usuarios.

Palabras clave: web interactiva; redes sociales virtuales; Facebook; hacer archivo; autonomía; imperativo del decir; gramática del medio; intervención autoral; campo intelectual argentino.

\footnotetext{
Artículo de investigación realizado en el marco de mis tareas como investigador de Conicet (Argentina), dentro de la línea "Producción cultural, intelectual, artística y tecnologías digitales". Asimismo, el trabajo se enmarca en las tareas desarrolladas como coordinador del programa de investigación "Nuevos frutos de las Indias occidentales: estudios de la cultura latinoamericana", asentado en el Centro de Estudios Avanzados de la Universidad Nacional de Córdoba (UNC), donde investigo sobre Teoría y práctica del archivo. El programa encabeza el proyecto de investigación "Archivos virtuales de artistas e intelectuales argentinos", con financiación de la UNC.

** Ciecs-Conicet, Argentina. Universidad Nacional de Córdoba, Argentina. diegovigna@gmail.com
} 


\title{
Autonomy and the imperative of the saying in the interactive web. A reflection on the file making in social networks from the current Argentine context
}

\begin{abstract}
For a decade and a half, the ways of filing and authorial intervention in web formats have invaded different spheres of action of the subjects, and have fostered behaviors of identity and cultural construction. Ways of registration and documentary organization that until recently seemed restricted to the study of institutional files, writers' files or other ways of preservation of cultural heritage, today model the daily practices of subjects that are involved with relational processes mediated by technologies. Within the framework of this problem, our objective is to reflect on the ways of making files in the context of virtual social networks, which we consider central to understanding the dynamics of intervention of subjects and groups in the interactive digital environment.

This reflection is based on a documentary analysis of the publications and user interventions in the most used social network in Argentina, Facebook, taking as empirical reference the last presidential campaign of 2015. The analysis is structured by considering each publication or post as a unit of content, following the principle of digital modularity. We took the 2015 presidential campaign in Argentina because, in its development, the interactive component was a key based on a premise of fundamental action arising from the analysis, which we call the imperative of the saying. This notion, within the framework of a specific publication and filing grammar, is central in order to understand strategies for capturing votes conceived from the supposed autonomy of users. Keywords: interactive website; virtual social networks; Facebook; make file; autonomy; imperative of the saying; grammar of the medium; author intervention Argentine intellectual field.
\end{abstract}

\section{Autonomia e imperativo do dizer na web interativa. Uma reflexão sobre o fazer arquivo em redes sociais a partir do contexto argentino atual}

\begin{abstract}
Resumo
Há uma década e meia, as formas de fazer arquivo e de intervenção autoral em formatos web invadem diferentes esferas de ação dos sujeitos e propiciam comportamentos de construção identitária e cultural. Formas de inscrição e de organização documental que, até pouco tempo, pareciam restringidas ao estudo sobre arquivos institucionais, arquivos de escritores ou outras formas de preservação do patrimônio cultural, hoje modelam práticas cotidianas de sujeitos que se envolvem com processos relacionais intermediados por tecnologias. No âmbito dessa problemática, nosso objetivo é refletir sobre as formas de fazer arquivo no contexto das redes sociais virtuais, as quais consideramos centrais para compreender a dinâmica de intervenção de sujeitos e grupos no ambiente digital interativo. A reflexão está apoiada numa análise documental das publicações e intervenções de usuários na rede social mais utilizada na Argentina, Facebook, tomando como referência empírica a campanha presidencial de 2015 desse país. A análise estrutura-se ao considerar cada publicação ou post como uma unidade de conteúdo, seguindo o princípio de modularidade digital. Tomamos essa campanha porque, em seu desenvolvimento, o componente interativo foi fundamental a partir de um princípio de ação fundamental surgido da análise, que denominamos imperativo do dizer. Essa noção, no contexto de uma gramática de publicação e arquivamento específica, é central para compreender estratégias de captação de votos concebidas a partir da suposta autonomização dos usuários.
\end{abstract}

Palavras-chave: autonomia; campo intelectual argentino; Facebook; fazer arquivo; gramática da mídia; imperativo do dizer; intervenção autoral; redes sociais virtuais; web interativa. 


\section{Introducción}

Desde el universo dedicado a comprender la relación entre tecnología y sociedad, cruzaremos perspectivas dispares como la teoría del archivo, la sociología y la filosofía de la técnica y la economía política de la comunicación con el objetivo de reflexionar sobre cómo las formas de pensar los archivos y, en consecuencia, lo que Jacques Derrida llamó las formas de hacer archivo son hoy centrales tanto para el sostén de la dinámica de intervención cotidiana de sujetos y grupos en el ambiente digital (sobre todo en sectores sociales medios y altos en Argentina, y cada vez más en sectores de menores ingresos), como para las implicancias que esa dinámica tiene en las estrategias e intereses económicos y políticos de las empresas y sectores de poder. Partimos de la posición que concibe a los grupos sociales en la coyuntura actual como constituidos por los vínculos técnicos, y hablamos de "formas centrales" porque el hacer archivo, desde hace al menos 15 años con la popularización de la Web interactiva o 2.0, ha invadido todas las esferas de acción (urbana), instituyendo conductas hoy corrientes y compartidas de construcción identitaria, cultural e intelectual a partir de las mediaciones técnicas digitales (Scolari, 2008). Lo que hasta hace poco parecía restringido a la investigación sobre la producción intelectual y artística (la existencia y el estudio de archivos institucionales, archivos de escritores, formas de preservación del patrimonio cultural e intelectual), hoy modela las prácticas cotidianas de sujetos que se identifican e involucran con procesos relacionales mediados por tecnologías y específicamente a través de las redes sociales virtuales, a partir del uso de dispositivos conectados en red. Esta es la problemática que abordamos a partir de las intervenciones de los usuarios en la red social más utilizada en Argentina, Facebook, tomando como referencia empírica la última campaña electoral de 2015, en la que el componente interactivo es clave para comprender estrategias de poder concebidas desde la supuesta autonomización de los usuarios (Castells, 2009). En esto se involucran distintos aspectos. Por ejemplo, cómo se construyen nuevas formas de intervención desde los medios interactivos, y cómo se ofrecen distintas variantes de participación, producción y recepción de contenidos en los "ciudadanos comunes" con acceso a dichos medios.

\section{Problema de investigación y método de análisis}

Buscamos mostrar cómo el hacer archivo se ha transformado en un reflejo dentro de los modos de ser y estar en el ambiente virtual, y cuáles son los instrumentos que popularizaron ese hacer archivo en el ambiente de las plataformas interactivas. Comenzaremos con antecedentes sobre el desarrollo de los formatos digitales, y utilizamos un aparato conceptual multidisciplinar articulado con la problemática y la observación. Los interrogantes que guían estas reflexiones son, en primer término, cómo es que las formas de hacer archivo en Facebook operan a la manera de "campo de prueba", en el contexto argentino, para definir estrategias de acción, económicas, políticas y culturales. Y a partir de lo anterior, un interrogante que enfoca la relación entre técnica y sociedad: a quién le sirve que hoy todos seamos (o pretendamos ser) productores de contenidos, según la premisa de un decir incesante. La base de lo que llamaremos au(di)toría automatizada. 
Con respecto al método de indagación y análisis, en esta instancia apelamos al análisis documental de publicaciones en perfiles específicos en redes sociales, considerando cada post como una unidad de contenido, a partir del principio de modularidad de Manovich (2005), y realizando la recolección de datos a través de capturas de imagen desde un perfil propio en Facebook. Partimos de la adecuación de ciertas premisas de la Grounded Theory (Glazer y Straus, 1967) para establecer una construcción de categorías que permita desarrollar la interpretación en simultáneo a la observación, recolección y análisis de datos, tal como Grillo (2008) recomienda para una investigación puramente cualitativa. Asimismo, la decisión metodológica de utilizar un perfil personal en redes sociales nos acerca a premisas de la etnografía virtual como el método observacional en su faceta digital, perspectiva que potencia el análisis interpretativo de los contenidos dada la naturaleza del objeto.

Apelar a elementos de la etnografía virtual es pertinente desde el momento en que debemos articular la observación e interpretación de discursos en las redes sociales, y las interacciones resultantes de dichas experiencias, con una reflexión sobre el cimiento de estas conductas y publicaciones, como es la dimensión cultural y política de Internet. En este sentido, el método observacional conjugado con el análisis documental nos permiten interrogarnos acerca de cómo afrontar las relaciones con el objeto, cómo pensar la construcción de estrategias discursivas, y cómo construir una perspectiva analítica desde el lugar de investigador.

En esta línea, Hine (2004) ha puesto el foco en las creencias que los usuarios tienen sobre Internet, considerando que estas modelan experiencias, prácticas y relaciones que se traman online. Esto llevaría a pensar que las intervenciones de los sujetos pueden dar cuenta tanto de nuevos modos de abordar las subjetividades expuestas en el contexto digital, como de pistas para leer, en la articulación con las gramáticas de los medios, los significados que van adquiriendo las tecnologías en las culturas que las propician y que, recíprocamente, también se ven influenciadas.

De modo que estas reflexiones marcan el comienzo de una indagación mayor en la que el diseño metodológico puede sufrir modificaciones, en el sentido de que articulamos el análisis documental con elementos que nos deben acercar tanto a la observación de conductas de usuarios-intervinientes en redes como a la observación de la dinámica de las gramáticas que permiten y restringen, al mismo tiempo, esas intervenciones.

\section{Internet, interactividad y el nuevo mundo de los productores}

El éxito de la Web 2.0 se forjó con la popularización del formato blog, que encontró su apogeo en Argentina entre 2005 y 2009 (Vigna, 2014). El blog fue caracterizado como el primer formato Web personal y relacional (Wrede, 2005; Fumero, 2005; Orihuela, 2004), que revolucionó las posibilidades de edición y difusión de voces y, al mismo tiempo, sentó las bases para el nacimiento de nuevas dinámicas de vinculación entre autores y lectores, productores y consumidores (Vigna, 2014). La cartografía de los blogs inauguró formas de 
conocerse y de expresarse, y la herramienta que propició esa revolución de la interactividad fue el hipertexto aplicado a la edición individual, ya que los servicios de blogging permitieron fusionar producción, edición y publicación. A manos del hipertexto, la gramática del blog ofreció la posibilidad de inscribir comentarios en las publicaciones, que podían ser moderados por los usuarios-administradores. Esa posibilidad de inscribir la propia voz ${ }^{1}$ en una publicación ajena se difundió, desde los emprendedores y programadores Web, como una nueva experiencia dialogal y de producción deslocalizada: los formatos digitales llegaban para que todos pudiéramos ser productores, y así difuminar jerarquías entre autores y lectores. Los comentarios en los posts renombraron las discusiones y las formas de agresión; con la atención que causó esta dinámica de foro inaugurada por espacios personales, incluso las versiones digitales de medios gráficos adaptaron sus sitios Web para que cada noticia pudiera ser intervenida por los lectores. Ese contagio entre sitios con intereses dispares prefiguró la promesa de Internet como medio superador: heterogeneidad, libertad de pensamiento y potencial expresivo, matices diseminados en millones de emisores vinculados en red.

Las redes sociales no tardaron en aparecer luego del campo de pruebas que significó el blog, e impactaron de lleno en los estudios específicos sobre Internet. Estas plataformas de comunicación crecieron notablemente en Latinoamérica, especialmente en Argentina y México, después de sus lanzamientos: Facebook en 2004, YouTube en 2005, Twitter en 2006 y Google+ en 2011, como ejemplos destacados (Magallanes, 2010). Las redes sociales radicalizaron el vértigo de los intercambios en una suerte de concentración que intentó ofrecer todo lo que los usuarios "suelen hacer en la Web" dentro de un solo espacio. En nuestro contexto, sin discutir las velocidades y ansiedades en la dinámica del intercambio, muchos usuarios desatendieron los blogs y se trasladaron a los servicios de microblogging (Twitter, Facebook, MySpace) para encauzar el registro de la cotidianeidad en primera persona, chats, promoción personal, difusión publicitaria; todo desde estructuras y gramáticas semejantes, con prioridad en las formas de visibilización que se fragmentaron y restringieron aún más que en los blogs. Esto significó una reinterpretación del broadcasting: cada perfil inscrito en una red social es único y autoadministrable, pero cada perfil produce de acuerdo con las condiciones de una plataforma donde todos ingresan para vivir la experiencia interactiva. A diferencia del rizoma heterogéneo de sitios que se encuentra por fuera del microblogging, las plataformas interactivas lograron consolidar núcleos de producción y reproducción de contenidos, donde cada usuario ingresa para producir voz, imagen y sonido, y compartir contenidos de distinta naturaleza a través de enlaces a otros nodos de la Web.

Las redes sociales agilizaron funciones que en los blogs se desarrollaron en forma incipiente. Sobre todo, el acto de compartir y recomendar contenidos a través de enlaces hipertextuales, interviniendo las plantillas ${ }^{2}$ personales. Y a partir de lo anterior, la interven-

El lenguaje en Internet pondera las situaciones de escritura, pero la ilusión dialogal que comenzó a expandirse en esos espacios tendió a simular matices de la oralidad a través de voces deslocalizadas (Vigna, 2014). Esa informalidad se agudizó en la dinámica de las redes sociales.

2 En el caso de Facebook, la plantilla es llamada "muro": se trata del NewsFeed, donde cada usuario puede acceder a los contenidos que sus contactos publican. 
ción más ágil que inauguraron estas plataformas: la opinión o evaluación sobre lo leído a través de una función de aceptación (en Facebook, Twitter o Instagram se ofrece como "Me gusta"), que luego se diversificó en otros sentimientos (tristeza, enojo, gracia, etc.).

De este modo, las redes sociales centralizaron el tránsito de información y de las dinámicas de exposición, publicación y del tiempo de permanencia en Internet a partir de la posibilidad de decir, opinar, participar y crear lo que cada uno desee desde su perfil, siempre dentro de la gramática (las restricciones y las reglas) ${ }^{3}$ de cada servicio. Dichas gramáticas se enfocaron en aumentar la velocidad de las intervenciones, bajo la premisa de que, en el mundo de la interactividad, y rediscutiendo las reglas de cada campo y subcampo de producción cultural (Bourdieu, 2002; 2010), todos somos potenciales productores debido a que estos servicios alteran las proporciones tradicionales entre productores (de imágenes y textos) y consumidores (Groys, 2014, p. 14).

En las redes sociales cada usuario establece su identidad a través de la imagen, en el contexto que cada plataforma impone (Groys, 2014). Esto ya forma parte de la cultura digital interactiva. Somos individuos reales en las calles y perfiles en nuestros espacios personales dentro del mundo interactivo, y así como Groys afirmó que en este contexto el arte debe ser analizado no desde la perspectiva del consumidor sino desde la del productor (2014), la necesaria ampliación de este deber alcanza a cualquier actividad y disciplina. Hoy, quienes intervenimos en la red, oficiamos con ambas máscaras: la de consumidor y la de productor, aunque estamos más pendientes en producir textos e imágenes que en consumirlos (Groys, 2014).

\section{Hacer archivo en las redes sociales. Imperativo del decir y au(di)toría automatizada en el buen uso de Facebook}

Con "formas de hacer archivo" intentamos ir más allá de la disciplina archivística. Podríamos citar una definición convencional de archivo que habla de un conjunto organizado de documentos, más allá de fechas, formas y soportes involucrados, que fue generado de modo arbitrario por un autor o interviniente y conservado para necesidades específicas (privadas o públicas) (Pené, 2013, p. 29); esta definición puede alcanzar, de hecho, al análisis del funcionamiento de los formatos Web. Sin embargo, apelamos a una mirada geneticista para incluir otras reverberaciones de las experiencias escriturales, que Derrida supo analizar a partir de las condiciones para que exista archivo. De este modo, proponemos pensar el hacer archivo desde lo que implica para el escribiente, y desde lo que significa la organización y la explotación de una obra en el ambiente técnico actual.

Para Derrida, las condiciones para que haya archivo (que siempre es, en origen, incompleto y transitorio) pueden comenzar a discutirse desde el momento en que algo se deposita en una exterioridad. No habría archivo si no hay conservación en algún soporte

Partiendo de su definición lingüística como conjunto de reglas para el "buen uso" de una lengua, algo que incluye a determinadas pautas combinatorias de elementos, pensamos aquí en una gramática sostenida en un proceso de automatización (Manovich, 2005) que explicamos en nota 4. 
por fuera de la memoria humana; es decir, no hay archivo sin topografía ni exterioridad (Derrida, 2013, p. 209). Esto es anterior al pensamiento archivístico porque cualquier gesto inicial de un autor sería previo a la constitución de un conjunto organizado de documentos, intervenidos y organizados. El gesto de un autor, por más espontáneo que sea, de consignar en un lugar exterior su palabra, implica una selección y un ejercicio de poder previo a cualquier operación crítica de selección e interpretación ejecutada por otro (2013, p. 210). Para Derrida hay archivo desde el deseo mismo de consignación en un soporte, porque allí comienza a debatirse una contradicción inherente al que escribe. Por un lado, no habría deseo de archivo sin la posibilidad de la pérdida y el olvido; Derrida sintetiza esto en la afirmación "escribo para guardar" (2013, p. 76). Por otro, quien escribe desea proteger la originalidad de su texto pero sobre todo "tiene ganas de no protegerlo", de que sea robado. "Cuando firmamos, queremos ser robados, y que el ladrón guarde la firma arrebatada", afirma (2013, p. 222-223). Desde esta posición, si pensamos el punto cero del hacer archivo desde la primera lectura de lo propio, el que intervenga luego eso producido no hará más que firmar sobre la firma de un autor (Derrida, 2013). Esto es importante para comprender los conceptos generados por la observación a partir de la gramática de las redes sociales. La condición digital, desde la mirada derrideana, ha reactualizado ese "permanente peligro" constitutivo del deseo de archivar.

Los conceptos de imperativo del decir y au(di)toría automatizada nacen de la articulación entre la observación empírica, la perspectiva sociotécnica y el análisis de las publicaciones. En forma un tanto críptica, Derrida amplió la idea de firmas sobre firmas y de ejercicios de selección y poder que nacen desde la inscripción misma de un pensamiento: dijo "el autor, el que firma es un censor. El censor o el archivista contra-firman. El archivista es siempre un censor. Es alguien que habilita, excluye, autoriza. Ese acto hace del censor un autor. Esto comienza ya con el autor [...]; la censura ha comenzado ya con la escritura" (2013, p. 224). La traducción de esta síntesis refleja que cualquiera que intervenga lo producido por alguien se convierte en un censor. Y ese acto de intervención lo convierte, a su vez, en autor, porque firma sobre la firma original. A eso Derrida le llama contrafirma. Pensando en el desarrollo anterior, en la dinámica incesante de producción de contenidos en las plataformas interactivas, este hacer archivo se basa en la supremacía de la contrafirma, que, a su vez, alimentaría la idea de Groys sobre la constatación de que hoy debemos ocupar la posición del productor. ¿Pero qué tipo de productor?

La au(di)toría automatizada se compone de tres conceptos fundidos en el primer término: autoría, auditoría, y el "di" que da cuenta del imperativo del decir. Lo automatizado remite a uno de los principios con que Lev Manovich (2005) caracteriza a los medios digitales, central para comprender la fusión de los conceptos señalados. Ampliamos luego cómo se ejecuta lo automatizado para comprender la naturaleza y las gramáticas de las plataformas, y también sería valioso detenernos en la noción de autor, pero exigiría un desarrollo extenso. En esta síntesis, tomamos al autor en su acepción clásica como "productor de contenidos originales", jugando un poco a oscilar entre la idea de creador y los interrogantes que el estructuralismo le opuso: quiénes crean a los creadores. Por su parte, la acción de auditar responde a un examen crítico y sistemático; etimológicamente 
el verbo viene del inglés "to audit", que significa revisar, intervenir. El acto de intervenir explica cómo se desenvuelve la producción de ideas, textos e imágenes en el universo de la Web 2.0, es decir, en el universo ubicuo del hacer archivo actual.

Si todo interviniente modifica el orden inicial de lo encontrado, podemos pensar que el universo de los formatos y plataformas 2.0 ha multiplicado exponencialmente a esta figura, aunque esta opera, pero "desbarata" a medias porque define su intervención según la gramática de cada medio. Por eso hablamos del carácter automatizado, siguiendo a Manovich (2005): una estructura y un abanico de acciones prediseñadas por los programadores de las plataformas (y por quienes toman las decisiones de programación: emprendedores, informáticos y programadores devenidos en empresarios) que, por un lado, alimentan el flujo constante de la red y permiten el registro inmediato de cada acción que ejecuta el usuario (2005, p. 77), y por otro, eliminan parte de la intencionalidad del proceso creativo al restringir el control de los usuarios sobre los procesos que tienen lugar en la plataforma ${ }^{4}$ (López y Ciuffoli, 2012, p. 28).

El que interviene en las redes sociales se somete al diseño, las funciones y las restricciones siempre a partir de un mandato común: el imperativo del decir, explícito en el caso de Facebook ${ }^{5}$. Esto se ofrece como el motor de las intervenciones de los usuarios. Quien decide intervenir ejerce todo acto de palabra desde un imperativo inicial que es recibido como un llamado a la posibilidad: tener a mano la posibilidad de ejercer nuestra libertad de expresión, opinión, evaluación, revisión, porque cada voz merece ser escuchada. La "libertad" diseñada por cada plataforma de publicación e interacción es global y moral: por un lado, hay otros (decenas, cientos, miles) esperando ser escuchados; por otro, esto ha inaugurado una moral propia de cada plataforma sintetizada en el decir para ser (visible). Y decir cuanto antes, porque así lo ponderan los algoritmos.

Cada gramática restringe la extensión de lo (re)producido y jerarquiza determinadas formas de textualización y expresión. No todos los grupos, estamentos, individuos que intervienen en las redes sociales comparten los mismos patrones morales, pero todos establecen uno. Y si hay algo que atraviesa, desde cada gramática particular, a todos los

Lo automatizado explica la conjunción algorítmica que define lo que llamamos la gramática de la red social, eso que "educa" necesariamente a cada au(di)tor. Cada intervención de un usuario es supuestamente mostrada en su actividad, en el NewsFeed, para todos sus contactos, pero la automatización define la relevancia de los contenidos publicados: la plataforma no muestra todo de la misma forma, con la misma insistencia o frecuencia. Como recogen López y Ciuffoli a partir de las ideas de Manovich (2005), el algoritmo que define el orden en que aparecen las publicaciones del usuario en Facebook se llama EgdeRank. Este algoritmo es el que "decide" qué es lo más interesante para cada usuario, en cada momento. Ese grado de interés lo define a través de tres factores. La "afinidad", que remite al grado de interacción entre el usuario y el creador del contenido: a mayor grado de interacción (de contrafirmas entre sujetos), mayor afinidad. La "relevancia" del contenido, en segundo término, que se basa en que, para Facebook, cuanta más interacción hay entre usuarios y una publicación, mayor calidad tiene la publicación, y por tanto merece mayor relevancia; esta fórmula explica la búsqueda de intervenciones de los au(di)tores. Cuantos más "Me gusta" o comentarios o shares, más posibilidades de que el contenido aparezca en otros muros. Y por último, el "tiempo": la velocidad impuesta por el medio. A mayor tiempo transcurrido desde que se publicó algo, en relación con la relevancia anterior, menor es la importancia del contenido. Según López y Ciuffoli, la vida útil de una publicación en Facebook no pasa las 24 horas $(2012$, p. 28).

5 La plataforma recibe a cada usuario con una pregunta: "¿Qué estás pensando?". 
patrones morales, es el solapamiento (el reemplazo) de los contenidos. Cada usuariointerviniente debe ser fragmentario para que el ritmo de las publicaciones sea eficaz: para que todas las voces tengan su lugar y se muestren. Otros parecen estar esperando nuestra voz, mientras todos dicen. Pero ¿cómo se articula con esta dinámica la constatación de que todos producimos contenidos? ¿Todo lo publicado es original? No: el au(di) tor, para ser autor en el minuto a minuto, se sostiene de esa gramática: las funciones de evaluación y revisión que propician estas plataformas (la supremacía de la contrafirma) nos sumergen en la ilusión del autor desde la mirada derrideana. Somos autores porque producimos contenidos originales, y también porque pasamos contenidos ajenos por el filtro de nuestra subjetividad. Este ejercicio de la autoría es parte de un diseño que implica el acto de censar o auditar, y eso define la interacción.

El autor-auditor con el decir impelido encabeza el ambiente interactivo donde la vinculación y la velocidad de los intercambios son los valores máximos, a veces ignorando el sentido de lo dicho. El vértigo de la transmisión de datos es el colchón donde descansan los productos y prácticas sociales, que se hacen visibles a través del discurso verbal o icónico y del hacer archivo permanente.

Cada productor de contenidos es también auditor porque ejerce, en la lectura, la revisión y reproducción (si así lo quiere) de lo leído y visto; cada cual puede administrar lo que recibe de otros autores-auditores: los puede silenciar, ignorar, recomendar. Cada usuario puede ver el valor de su intervención porque así lo afirma la gramática de cada plataforma; si no puede crear, debe decir a qué vale atender, qué vale la pena reverberar. El círculo de velocidades y solapamientos de información que es producto de esta forma de estar en las redes sociales tiene relación con el carácter autónomo de nuestras conductas, por cómo y cuánto es alimentado, pero: ¿es determinado por la acción de los usuarios, por el diseño de la plataforma, por el tiempo mismo en su devenir? Desde hace más de una década, estas estrategias de comunicación y publicación de contenidos son concebidas como forma de construir un intercambio superador de la información, que para algunos teóricos amplía las capacidades de autonomización de los sujetos.

En el deseo intrínseco, y contradictorio, del "querer ser autores para ser robados" de Derrida, aquí traducido a querer ser autores para ser intervenidos, revisados, reproducidos, se transparenta este orden que alimentamos y que ha obligado a repensar formas de identificación, de vinculación, de estar en el mundo real: el hacer archivo automatizado como forma de ser considerado por el otro (un imaginario). En el universo de las pantallas, en medio de la lógica relacional, solo existe lo que se ve. Así deviene la forma global y a la vez íntima de poner en juego la fiebre contradictoria de archivo, ese "mal" al decir de Derrida: mal de archivo en el que no participan solo los sujetos aislados, sino que lo hacen sectores, grupos, formas de acción con intereses específicos, aunque cada red social proponga limar las jerarquías entre individuos y colectivos y se ofrezca como reflejo de la libertad de los usuarios. ¿Por qué apostar a hacer archivo minuto a minuto? ¿A quién le sirve, y para qué, que todos seamos productores y que los contenidos sobreabunden? Citaremos como referencia empírica el caso de la campaña electoral de 
la alianza Cambiemos en Argentina, en 2015, para mostrar cómo se realimenta, según estrategias e intereses particulares, la au(di)toría automatizada. Pero antes ampliamos la cuestión técnica para comprender cómo se desarrolló Facebook en tanto archivo, con sus formas propias de hacer archivo. Luego recogemos algunas reflexiones que dieron cuenta de la tensión entre la autonomía propiciada por la Web y el imperativo del decir en las plataformas sociales.

\section{La gramática de Facebook. Algoritmos y desarrollo empresarial para captar usuarios, datos e interacciones}

La gramática de Facebook se basa en los principios con que Manovich caracteriza a los medios digitales. Lo automatizado se materializa en algoritmos, pero proviene de principios anteriores: la automatización nace de la "representación numérica" (Manovich, 2005, p. 75), esto es, de la condición digital que permite acceder a los "objetos" en estos medios a través de algoritmos, y del "principio de modularidad" relacionado con lo anterior: la condición discreta en que se ofrecen y ordenan los elementos en el medio. En el caso de Facebook, los objetos se agrupan por colecciones (imágenes, textos, videos) que no eliminan la identidad de cada objeto por separado. Esta es la base del diseño de perfil de usuario, la Biografía, donde cada bloque de contenido destaca acontecimientos en la vida de los usuarios porque cada perfil expone una historia personal, aunque los contenidos no remitan al sujeto (López y Ciuffoli, 2012, pp. 25-26).

Sin embargo, la forma que tiene hoy Facebook, con tan aceitada dinámica de reproducción de contenidos desde una línea de tiempo personal no fue siempre así. Su caracterización pasó de una red de universitarios (2004-2006) a una red pública, para finalmente divulgarse como red masiva y abierta hasta 2010 y después como una web social y personalizada (López y Ciuffoli, 2012). Luego de la incorporación de las primeras funciones (crear grupos, en 2004; publicar fotos, en 2005; conectarse con móviles y publicar notas en 2006), el servicio permitió la inclusión de anunciantes en perfiles personales y grupos, y consolidó la dinámica del NewsFeed (plantilla donde cada usuario ve las publicaciones de otros, y las publicidades) y el MiniFeed (cada post publicado por un usuario) como elementos centrales de los que López y Ciuffoli llaman "streaming personal" (2012). La apertura de Facebook a otros espacios, dentro y fuera de la plataforma, se produjo con el lanzamiento de las funciones Compartir (share), que permite (re)publicar posts de otros usuarios en el perfil propio, y la de Insertar (embed), que permite publicar contenidos de otros sitios Web en nuestra Biografía (López y Ciuffoli, 2012). Es decir: contrafirmar. En 2009 se lanzó el elemento decisivo para imponer esa lógica de la contrafirma: el botón "Me gusta".

Con la aplicación Facebook Connect se abrió el camino para que los usuarios pudiesen utilizar su identidad de Facebook en otros sitios web y blogs visitados. Eso llevó a que cada nota leída o comentario inscrito por un usuario en otro sitio pudiera ser replicado en su NewsFeed, lo que amplió la visibilidad en Facebook a las empresas o medios que generan contenidos. Así, cada au(di)tor lleva a "su Facebook" contenidos creados fuera de la plataforma (López y Ciuffoli, 2012). Por su parte, estos intereses externos encontraron en la 
función del "Me gusta" (hoy diversificado) un nuevo campo de acción, aprovechando la ponderación de los algoritmos para medir intereses y conductas. A esto, llamativamente, se lo señaló como "el despegue de la experiencia de navegación más social y personalizada" por lo que permitió: acceder a la base de datos de los usuarios (López y Ciuffoli, 2012). Esto replanteó la relación entre Facebook y las empresas de medios, que utilizaron estas funciones para lograr mayor visibilidad entre los usuarios a partir de la au(di)toría automatizada: son ellos los que aparecen como (re)productores de los contenidos que consumen, filtran y contrafirman, no los medios. "A través de esa aplicación los usuarios comparten lo que están haciendo, escuchando, leyendo [...] El abanico de posibilidades que se abre plantea [...] la integración y retroalimentación de información específica sobre gustos, preferencias e intereses de los usuarios" (2012, p. 31).

Otra modificación que Facebook realizó en su gramática es la herramienta de monitorización Facebook Insights, que permite a marcas, políticos y medios de comunicación acceder a información precisa: cuántos usuarios están hablando de su página, o la cantidad de interacciones que tiene una publicación específica (López y Ciuffoli, 2012, p. 20). De modo que queda clara la síntesis que López y Ciuffoli hicieron sobre esta evolución: el paso de una red social a un medio de información y comunicación que "aglutina usuarios/ audiencias alrededor de contenidos y se sustenta en un modelo publicitario. La novedad que introduce es que el contenido es creado por los usuarios" (2012, p. 21). A nosotros nos interesa resaltar eso: quién crea qué, con qué fin, y si esto tiene relación con la autonomización de los sujetos.

\section{Estudios sobre Web 2.0 y la pregunta por la autonomía en la apropiación y el uso de dispositivos}

Sumergidos en las precisiones técnicas, apelamos a la perspectiva sociocultural para abordar el concepto de autonomía desde una mirada crítica. Como ha sintetizado Magallanes, al nivel regional los estudios sobre Internet y la cibercultura se vienen desarrollando en términos de mediaciones sociales, económicas y culturales para dar cuenta de las interacciones entre sujetos y grupos (2010); en el corazón de los estudios de medios, este desarrollo se alineó con la tradición de estudios de recepción latinoamericanos, hasta hace dos décadas todavía atentos al concepto de "audiencia" para comprender la dinámica de los medios de comunicación convencionales.

Los medios digitales, como afirmó Livingstone (2005), pusieron en jaque a los investigadores de audiencias gracias a la irrupción de la convergencia de lenguajes y la interactividad. Lo interesante de ese movimiento en los estudios de medios es que algunas discusiones conceptuales sobre lo anterior ubicaron a los estudios de Internet lejos del concepto de audiencia para enfatizar más los rasgos interactivos, hipertextuales y reticulares (Magallanes, 2010), mientras que los investigadores de audiencias tendieron a dejar de lado la actividad creativa producida en la lógica de la comunicación digital (Flores Márquez, 2012). 
A caballo de los cambios en los formatos interactivos, estos conceptos comenzaron a articularse. Y han tenido especial difusión estudios como los de Castells, que se han dedicado a historizar y describir el desarrollo de las redes de comunicación informáticas, Internet y la Web. En Comunicación y poder (2009) Castells se dedicó entre otras cuestiones a la vinculación entre la interactividad y la autonomía de los sujetos. La base de sus estudios partió de la omnipresencia de la red de comunicación electrónica: con estos servicios, las comunidades en línea crecen no como un mundo virtual sino como una virtualidad real integrada en otras formas de interacción, en una cotidianeidad cada vez más híbrida (2009). La interacción a través de redes está en todo lo que hacemos, según Castells, sobre todo para millones de usuarios de edad media. Esto incluye fundamentalmente a los países en desarrollo, cuyo único obstáculo (no menor) es la limitación en el acceso.

Castells afirmaba en 2009 que de la interacción entre redes verticales y horizontales de comunicación surgiría una nueva realidad mediática cuyos efectos se decidirían en las luchas por el poder político y empresarial a medida que los dueños de las redes de telecomunicación tomaran posiciones para controlar el tráfico a favor de clientes privilegiados. Su posición era ambigua: por un lado, acentuando la idea de autonomía que propiciarían las redes, según sus estudios empíricos; por otro, afirmando que su noción de "autocomunicación de masas" (comunicación de "muchos para muchos", distinta del broadcasting conocido, propiciada por los espacios Web que llega a una audiencia global) daba cuenta del "creciente interés de los medios de comunicación corporativos por las formas de comunicación basadas en Internet" (2009, p. 108).

Con la autocomunicación de masas, Castells encuentra a los contenidos como "autogenerados" y la recepción "autoseleccionada" por todos aquellos que se comunican. Sin embargo, en la dinámica de Facebook, cada usuario ve en su NewsFeed más de lo que "debería" ver según los contenidos que producen sus contactos: el medio impone. Castells no se posicionaba desde el determinismo ("el medio, incluso un medio tan revolucionario como este, no determina el contenido ni el efecto de sus mensajes" decía [2009, p. 108]), pero defendía el potencial de Internet para hacer posible una diversidad ilimitada y una producción autónoma de la mayoría de los flujos de comunicación que construyen el significado en el imaginario colectivo (2009). Siete años después de esa afirmación, la situación parece distinta por el movimiento entre los emprendedores, los programadores de las redes y los intereses de las principales corporaciones que brindan servicios: Google, Apple, Facebook, Amazon, sin contar otras redes sociales. El signo del momento en la Web parece ser la creciente tensión entre proyectos y productos autónomos (que han utilizado formatos como el blog) y el poderío de corporaciones que contemplan estrategias y conglomerados de servicios para instalar, a través de la gramática de las plataformas interactivas, prioridades en la diseminación de discursos e imágenes.

\section{La autonomía y el lugar de los usuarios: sobre la audiencia creativa en Castells}

Castells ya afirmaba en 2009 que las organizaciones relacionadas con la comercialización de servicios en Internet estaban influidas en gran medida por las estrategias empresa- 
riales de rentabilidad y expansión de mercados que modelan (aunque no determinan) el desarrollo de las tecnologías de la comunicación, y sobre todo la "bajada a tierra" de estos procesos para usuarios no especializados: lo que llamó "las nuevas culturas de comunicación autónoma". El diagnóstico también parece ambiguo: Castells decía que "si bien el crecimiento de la autocomunicación de masas aumenta la autonomía y la libertad de los actores de la comunicación, dicha autonomía tecnológica y cultural no conlleva necesariamente la autonomía respecto a las empresas mediáticas" (2009, p. 111). Entonces, ¿qué autonomía se discute?

Según Castells (2009), al momento en que se reconoció a Internet como una forma decisiva de comunicación, se multiplicó el deseo empresarial. Pero la cultura original de Internet lo rechazaba, por lo que comenzaron los movimientos de preservación por parte de usuarios, instituciones y comunidades que buscaron crear organismos de regulación. La autonomía que buscaron mantener esos actores, en pos de fomentar el crecimiento de un espacio de experimentación, sociabilidad y expresión cultural independiente, fue renombrada por el desarrollo de la Web interactiva, que llevó a replantear la relación capital-Estado gracias a su potencial. Las empresas surgidas de la figura del emprendedor (sujetos con ideas innovadoras que buscaron financiarse para brindar un servicio social, luego diversificado en otros productos) reorientar las estrategias hacia la creación de plataformas donde la intervención de los sujetos fuera el eje de la creación de contenidos y el modelo de interacción social. De modo que mientras la atención del mundo se centraba en la libertad de expresión de Internet, las estrategias de construcción de poder a través de la articulación de intereses se desarrollaban a partir de la elección de los consumidores (Castells, 2009).

El terreno en disputa pasó a ser la relación entre capital y Estado que generó la formación de redes de empresas multimedia; según Castells, con esta arquitectura macro los intereses empresariales prevalecen en su interacción con el Estado, y las empresas ven un gran campo de inversión en la auto-comunicación de masas. Esas son las condiciones en las que las audiencias se transformaron en un "sujeto comunicador" capaz de redefinir los procesos con los que la comunicación enmarca la cultura de la sociedad (Castells, 2009). Ahora bien: vale la pena pensar qué capacidad real tiene ese "sujeto comunicador" para definir procesos o contenidos, porque ese parece el objetivo de las empresas de medios digitales: que los algoritmos que regulan las redes sociales ponderen la producción de los usuarios más que los contenidos y procesos. Las intervenciones de los au(di)tores se visibilizan allí más que otros contenidos producidos en otros sitios Web; el carácter automatizado de estas lógicas busca que sean los usuarios quienes "decidan" qué decir, pero con la "autonomía" que los medios definen, porque los usuarios no toman decisiones al nivel de programación. Estos procesos se sostienen en patrones de conexión interactivos, lo que Castells llama la "cultura de la coproducción de contenido". Según dice, "en nuestra sociedad los protocolos de comunicación no se basan en compartir una cultura sino en la cultura de compartir" (2009, p. 177).

La audiencia creativa, superadora de la pasividad de las audiencias en los medios de comunicación de masas, sería desde esta posición reproductora de la cultura de la 
autonomía reformulando, por un lado, la relación con las instituciones de la sociedad (los usuarios pueden expresarse por sí mismos, sin editores o censores), y por otro, replanteando las formas tradicionales de comunicación. Según Castells, la difusión de Internet y la comunicación inalámbrica (los dispositivos móviles) refuerzan las prácticas de autonomía con la posibilidad de "subir" a la red contenidos producidos por usuarios (la ubicuidad de la intervención autoral). Dice:

Estudiando los usos de Internet de las personas encuestadas y comparándolos con sus índices de autonomía, vimos que cuanto mayor era el nivel de autonomía, en cualquiera de las dimensiones, mayores eran la frecuencia e intensidad del uso de Internet. Y cuanto más usaban Internet, más aumentaba su nivel de autonomía. Por tanto, en nuestro estudio se ha comprobado empíricamente la percepción común de Internet como instrumento de construcción de autonomía (2009, p. 181).

¿Cómo se establece ese índice de autonomía, y a quién favorece esa percepción en esta coyuntura de popularización de redes sociales? ¿Mediante qué procesos se define lo que luego ejecutan programadores y diseñadores? ¿Quiénes deciden la ponderación en la visibilidad de los contenidos, mientras los au(di)tores somos cada vez más autónomos en la apropiación de sus herramientas?

Castells no profundiza en estos aspectos. Su análisis llega a afirmar que de la comunicación dirigida a una audiencia hemos pasado a una audiencia activa que forja su significado comparando su experiencia con los flujos unidireccionales de la información que recibe, y que la autonomía se materializa en la producción interactiva de significado (2009). Nos interesa este corte analítico porque sus consideraciones sobre las formas de coproducción de contenidos han llegado hasta artículos más recientes, donde sí enfatiza en la especificidad de nuestro objeto, pero al nivel cuantitativo: en 2014 afirmaba que, siguiendo su historización, en 2009 las redes sociales ya tenían mayor número de usuarios que el correo electrónico, mientras en que 2010 habían alcanzado los mil millones de usuarios, la mitad de ellos en Facebook. En 2013 se había duplicado ese número debido a la extensión del uso en regiones como América Latina y países como China e India (Castells, 2014).

¿Cómo reverbera, entonces, en el archivo incesante, pero efímero de las redes sociales, la instalación de significantes y la producción interactiva de significados? ¿Qué sucede con la articulación capital-Estado si las empresas que definen la gramática de estos intercambios establecen acuerdos específicos con sectores políticos, como en el caso argentino? ¿Cómo trabaja esa instalación de significantes para que la producción de información se funda con la intervención de los usuarios, y así interpele directamente la recepción-producción de los usuarios-intervinientes? La base de cualquier respuesta es, en principio, la gramática del medio en su virtuosa redefinición recíproca: formas, funciones y diseños estipulados para que los usuarios alimenten las plataformas expresándose libremente, mientras los muros siguen acumulando contenidos.

La audiencia creativa es lo que caracteriza a la auto-comunicación de masas. Pero esa autocomunicación hoy se debate entre proyectos autónomos, por fuera de las redes 
sociales, y plataformas que naturalizan estas variantes de la autoría que intervienen en un hacer archivo diario. Las gramáticas de (hacer) archivo establecen posibilidades: más allá de las diferencias culturales en las que se inserten cada sujeto o grupo, el ambiente técnico capitaliza las intervenciones para redefinir permanentemente las "buenas formas". Por eso la gramática es definitoria. ¿Qué clase de contenidos y acontecimientos creamos? En las redes sociales, ¿importa más el contenido o el acontecimiento?

\section{La campaña de Cambiemos en Argentina y su llegada al poder. El imperativo del decir como herramienta de construcción de un candidato}

Las elecciones presidenciales en Argentina durante 2015 tuvieron como novedad la atención que las fuerzas políticas brindaron a las redes sociales como espacios estratégicos para captar votos. El caso del candidato ganador, Mauricio Macri, de la alianza Cambiemos, da cuenta de la importancia que adquiere una posición crítica que atraviese las distintas perspectivas para abordar estos fenómenos.

Julián Gallo, jefe de campaña del candidato presidencial, expuso en una nota pública cómo se planeó la campaña: Gallo definió a Macri como el "primer presidente de Facebook", remarcando que es "uno de los tres medios digitales más importantes de la Argentina", y de acuerdo con el grado de interacciones en su página, el más popular (2015).

En este planteo del candidato como medio Gallo comparó sus indicadores cuantitativos de popularidad con indicadores del diario New York Times, para luego afirmar que la comunicación de campaña, con las acciones en Facebook incluidas, fueron "una extensión del cuerpo" de Macri (2015). Esto implicó, para los arquitectos de campaña, pensar en "las personas que iban a leer, ver e interactuar con sus contenidos, como una audiencia cuyas reacciones y su comportamiento serían significativos": la gente iba a hablar con Macri, a firmar sobre su firma para sentirse parte. Aprovechando el ida y vuelta entre los usuarios y la gramática de Facebook, la estrategia operó en el medio de las posiciones vistas: un candidato puede pretender ser un medio de comunicación, la gente puede hablar con él como lo hacen las audiencias, pero "no solamente con mensajes e interacciones, sino también con su conducta" (Gallo, 2015). Por otra parte, a diferencia de los medios convencionales, el candidato fue presentado en Facebook a partir de expresiones alejadas de la política y los temas coyunturales. Según Gallo, Macri "se contó a sí mismo" mostrando su interés por los animales, "los momentos compartidos con su hija o su esposa, sus opiniones espontáneas" (2015); todo respondiendo a la ilusión de que Facebook es parte de la vida. En palabras de Gallo, un largo proceso en el que la gente, gracias a esas intervenciones del candidato como "un usuario más", se fue "contactando emocionalmente con su estilo directo y personal, que permitió que Macri pudiera expresar sus ideas, pero también sus emociones, sus alegrías, su entusiasmo, su anhelo de ser presidente" (2015).

La apuesta fuerte, en medio del hacer archivo y las reverberaciones semióticas y sociotécnicas de las intervenciones de los usuarios, fue la decisión de que Macri "interpelara" directamente a sus seguidores, desde la plataforma, con consignas como 

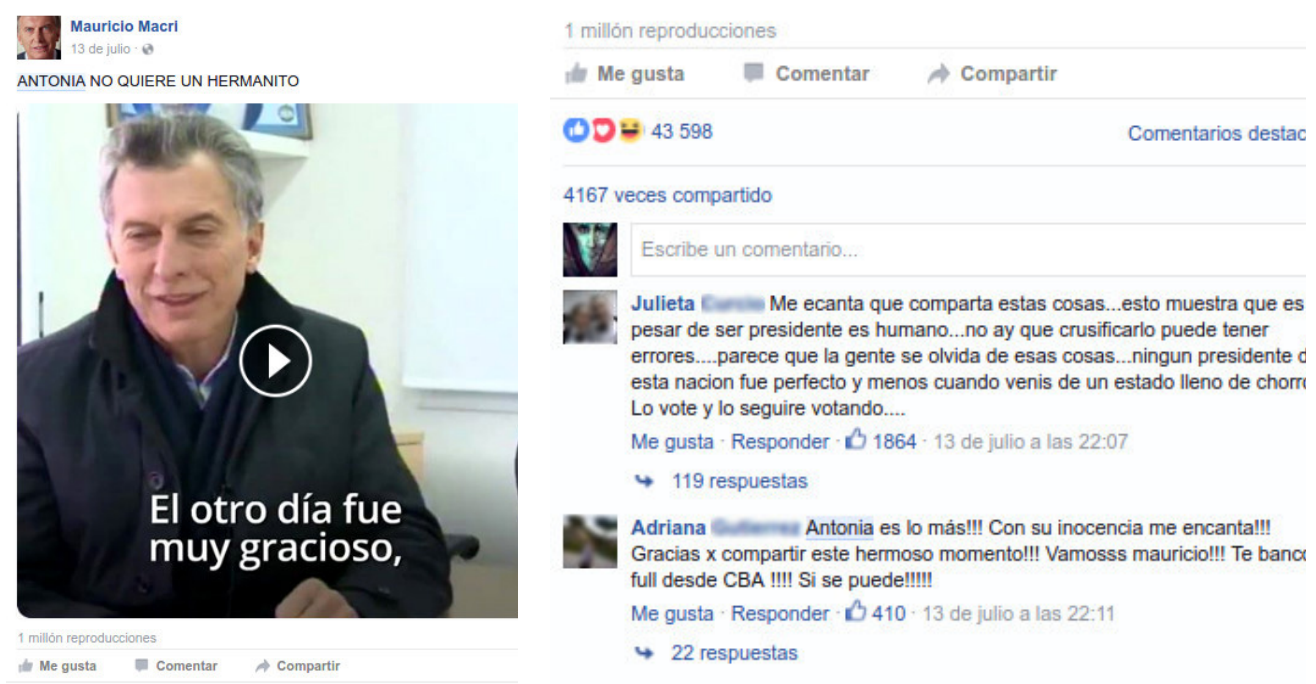

Gráficas 1 y 2. Publicación de Mauricio Macri en su Biografía de Facebook, con extracto de las intervenciones de usuarios. 13/07/16 [Captura de imagen, cuenta personal, 06/09/16]

"Quiero ir a tu casa". De ese modo, el candidato visitó usuarios "que lo habían invitado a sus propios hogares. Cada casa, cada familia, cada historia se convertía luego en un post en Facebook", describe Gallo (2015). Y ofreció como ejemplo el caso de una mujer que, luego de leer la consigna, intervino allí mismo con un comentario: "Sé que no vas a venir, pero igual te espero, Mauricio". La mujer fue elegida y el candidato llegó a "su humilde casa con piso de tierra a comer ravioles y a escuchar sus problemas" (Gallo, 2015). Es decir, el imperativo del decir aplicado. Según Gallo, "la fanpage de Macri fue el medio que permitió contar la historia de Sandra, y muchas otras, a cientos de miles de personas" (2015).

Aportando al interrogante sobre las relaciones entre capital-Estado que enmarcan estas estrategias, fueron varias las acciones de la alianza Cambiemos una vez en ejercicio del poder. Por un lado, en el Ejecutivo comenzó a operar un equipo de especialistas en redes con un doble objetivo difundido en medios de prensa: en primer término, influir en redes sociales y cuidar la imagen de Macri frente a la injerencia de los medios de comunicación tradicionales ("Cómo opera el Gobierno...", 2016). Esto se realiza con la creación y difusión de vídeos y consignas en Facebook, Snapchat, Instragram y Twitter desde las cuentas personales de Macri, con especial énfasis en Facebook porque esta plataforma, como afirmó Bogado (2016), es la más importante para filtrar la distribución de noticias "convencionales". Y el filtro, en un medio donde más de 10 millones de personas reciben los decires familieros del presidente, es fundamental para instalar significantes que operen como contrapeso en situaciones de coyuntura. En segundo término, negado por el Gobierno en ejercicio, pero sí aceptado durante sus acciones de campaña, ese recurso institucional se complementó con la administración de grupos de usuarios de redes falsos dedicados a operar sobre la 
MERCADO LIBRE INVERTIRÁ 1500 MILLONES

Esta mañana acompañamos el anuncio de inversiones de Mercado Libre para los próximos cuatro años, que incluyen la inauguración de 23.000 metros cuadrados más de oficinas y la creación de 5.000 nuevos puestos de trabajo.

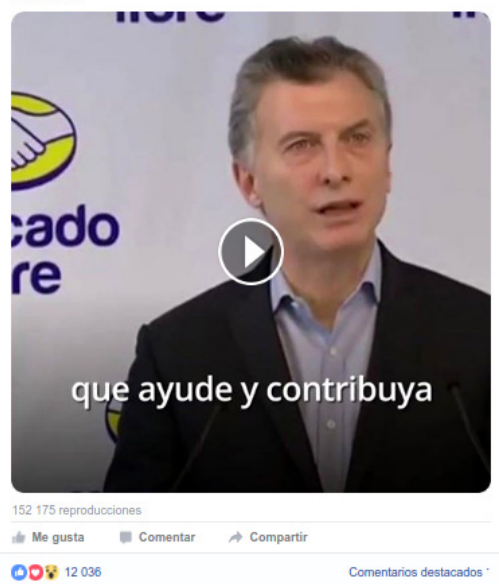

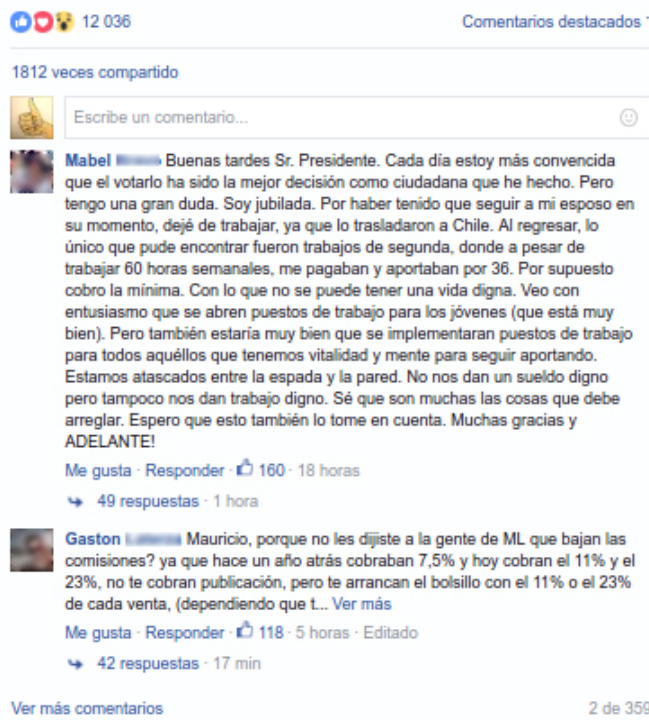

Gráficas 3 y 4. Publicación de Mauricio Macri en su Biografía de Facebook, con extracto de las intervenciones de usuarios. 17/08/16. [Captura de imagen, cuenta personal, 17/08/16]

agenda diaria ${ }^{6}$. Todas estas maniobras se efectúan bajo la premisa de la comunicación personalizada, con una segmentación de mensajes por zona, edad, género e intereses en todas las redes sociales ("Cómo opera el gobierno...", 2016). Para manejar esos datos, los convenios entre el aparato estatal y la base de datos que administran las redes sociales es decisivo. En el medio queda la libertad de los usuarios opinando y brindando información textual y contextual a partir de las intervenciones "mundanas" del presidente.

Por otro lado, Macri dispuso el lanzamiento de un plan para implementar desde el Ejecutivo Nacional la plataforma social de uso interno Facebook at work. Esto se llevó a cabo luego de una reunión con una responsable de la empresa con la que, además, sentaron las bases para que dicha red social implementara en Argentina servicios mediante aplicaciones móviles con la finalidad de "aumentar la penetración de Internet en países en desarrollo" (Presidencia de la Nación, 2016).

Queda pendiente la profundización de estas cuestiones para ahondar en los intereses puestos en juego, aunque el mismo presidente se ha ocupado de hacerlo explícito: Macri encabeza desde su discurso un perfil político-económico dedicado a destacar la "cultura del emprendimiento", base ideológica y práctica que, como hemos señalado, sostiene el desarrollo de la infraestructura y los servicios de medios digitales. "Seamos un país de 40 millones de emprendedores", afirmó Macri en su plataforma de campaña. José Natanson definió al emprendedor como el "héroe capitalista del siglo XXI": no es un empresario más,

\footnotetext{
Para profundizar esto: http://www.perfil.com/politica/como-opera-el-gobierno-en-las-redes-sociales-0326-0052.
} phtml?utm_source=redir_url__legacy 
sino un innovador más relacionado con la "inteligencia emocional" -nótese el vínculo con las estrategias descritas en campaña para "llegar a los usuarios" de Facebook- que con la construcción de conocimientos duros. Los rasgos de los emprendedores serían la creatividad, la flexibilidad y el liderazgo como atributos opuestos a viejas formas económicas. "Sus encarnaciones más emblemáticas", dice Natanson, "son Mark Zuckerberg, el creador de Facebook, y Steve Jobs, fundador de Apple" (2016).

En relación con el contexto argentino, la figura del emprendedor es central en el imaginario del Gobierno, y en la praxis política: fueron designados varios funcionarios relacionados con el mundo de la "economía creativa" (ex CEO de empresas de servicios de comunicación, turismo, innovación productiva). Es así que la sintonía entre el perfil liberal de un Gobierno que propone un quiebre "modernizador", y la exaltación del emprendimiento, raíz del fenómeno que nos incumbe, encuentra para Natanson (2016) un límite en las coordenadas espacio-temporales: esta política en el mejor de los casos repercute solo en un sector social reducido y con recursos. Esto potencia lo señalado en torno a las estrategias mediáticas, económicas y políticas que se sostienen en el imperativo del decir: el emprendimiento se limita a una estrecha fracción social, pero la posibilidad de crear un perfil y apelar a (re)producción de contenidos es de todo aquel que pueda hacerse de un dispositivo y conectarse a una red social. La asimetría parece estar en la base de la ilusión por la participación y la autonomía de los usuarios-intervinientes: tenemos las plataformas, sus herramientas y sus gramáticas a disposición para ser más autónomos a la hora de expresarnos y de recibir información de otros, pero pocos podemos adentrarnos en los procesos que definen y diseñan esas herramientas, y para reflexionar sobre ellos en el hacer cotidiano de la palabra.

\section{Conclusiones}

Toda red social es un archivo en sí mismo y, a la vez, una propuesta sobre formas de archivar. Cada plataforma interactiva indica cómo debe hacer el usuario para hacer archivo. La gramática de cada plataforma define cómo se inscribe, cómo se accede y cómo se ve lo producido; cada gramática nos dice qué tipo de autores seremos en cada contexto particular. En Facebook, la Biografía personal es la matriz de archivo que asumimos y alimentamos. Y el contenido abismal y siempre en movimiento de cada uno de estos medios es de libre interpretación, como cualquier otro archivo convencional.

Quién hubiese dicho, en este contexto, que una actividad antes restringida a pocas disciplinas como el hacer archivo, de concepción bastante estática, luego se configuraría como un vector que permite expandir la lógica de la velocidad, la interactividad y la producción discursiva (el tan buscado fluir de la información) en pos de alimentar el tráfico de datos. Quién hubiese dicho que algo a primera vista tan improductivo como la simple inscripción cotidiana del pensamiento en una exterioridad terminaría siendo un motor de estrategias de injerencia mediática, cultural, política, económica: una nueva variante de la rentabilidad. En el interrogante de qué se esconde detrás del deseo de autonomía (traducción: el deseo de la comunicación en sí misma) y de la producción incesante de 
discursos (premisa capitalizada por emprendedores, programadores y corporaciones), parece desenvolverse una lógica no solo de rédito económico, sino que también comprende a la cuestión política como forma de disputa de poder.

Esto, por otra parte, excede a nuestra referencia empírica porque habla de una concepción de la palabra en el ambiente digital, en el seno de la asimilación cotidiana de soportes inmateriales. Esto, incluso, nos pone de cara a nuevas formas de la compulsión y de la concepción del yo, que en virtud de la naturalización de ciertas prácticas parecen hablar tanto de la coyuntura mediática, económica y política como de la autopercepción de los sujetos en relación con el entorno y con las formas de atravesar el tiempo. El "decir para ser" es una premisa que merece ser puesta a prueba en futuros análisis, en el marco de cómo devengan estas dinámicas, y de interrogarse sobre el lugar que ocupará, en los próximos años, el ejercicio (ilusorio o real según la perspectiva desde la que se lo mire) de la autoría. Pero, sobre todo, estos fenómenos abren interrogantes acerca de la perennidad de las ideas, en el contexto de un hacer archivo compulsivo.

Desde la perspectiva económico-política de Castells, que concibe la discusión por la autonomía desde la tensión entre la infraestructura comunicacional, las estrategias empresariales y públicas y el lugar del usuario, José Van Dijck (2016) ha discutido los límites de esta mirada. Si hablamos de una articulación entre la autonomía que la red fomenta en los usuarios y el rédito que las corporaciones le sacan a esa "sensación" llevada a la praxis, en el medio queda la relación fundamental entre todos los productores, au(di)tores según nuestra reflexión, y los contenidos. Entre esos choques opera la discusión sobre la influencia real y recíproca que existe entre los usuarios y estas formas de archivo basadas en un abanico dispar de variantes de interacción. Según Van Dijck (2016), mientras más influyen los usuarios en la gramática de Facebook, más información detallada obtiene la plataforma, útil para todos sus fines. Es la conectividad una calle de dos manos, en la que las redes sociales se asocian, comparan e inauguran una cultura del intercambio en el que cada una muta según las alteraciones en otras plataformas (muchas veces propiedad de los mismos emprendedores) (Bogado, 2016). Esa reciprocidad no atenta contra las gramáticas sino que las perfecciona: no se trata de quedar de un lado u otro del determinismo sino de actualizar y repensar la idea de Andrew Feenberg (2009) de que ningún dispositivo surgió plenamente de la lógica de su funcionamiento. Por eso cerramos con interrogantes desde una perspectiva filosófica. Para Feemberg, el perfeccionamiento de un objeto técnico (y, podríamos decir, la naturalización de una conducta técnica) muchas veces borra las huellas de la mano de obra que lo construyó, y las fuerzas sociales que estaban en juego durante su diseño. Creemos decisivas esas huellas para seguir reconociendo y discutiendo los valores que dominan la creación, porque las tecnologías son la expresión cristalizada de esos valores, y ni la sociedad ni las tecnologías pueden entenderse aisladamente (Feenberg, 2009). ¿Cuál es el precio actual, y cuál será el precio a futuro, de esa autonomía que ponemos en discurso constante con estas rutinas de intervención, en medio de lo que Feenberg llamó "la jerarquía enredada"7 en la relación tecnología-sociedad? Las me-

Según Feenberg, los grupos sociales están constituidos por vínculos técnicos que relacionan a los miembros, pero éstos reaccionan a esos vínculos según los términos de su experiencia. Así los grupos, una vez conscientes de su 
diaciones parecen apuntar a seguir modelando identidades y experiencias; deberemos ahondar en las políticas de la tecnología, y en las expresiones artísticas, para vislumbrar lo que subyace, las consecuencias de la conectividad y su realimentación.

\section{Referencias bibliográficas}

Bogado, F. (2016), "Una calle de dos manos". Suplemento Radar, Página/12, 28 de agosto. Buenos Aires, Argentina. Recuperado en febrero de 2016 http://www.paginal 2.com.ar/diario/suplementos/ libros/10-5919-2016-08-28.html

Bourdieu, P. (2002), Las reglas del arte. Génesis y estructura del campo literario. Barcelona: Anagrama.

. (2010), El sentido social del gusto. Buenos Aires: Siglo XXI.

Castells, M. (2009), Comunicación y poder. Madrid: Alianza Editorial.

(2014), "El impacto de Internet en la sociedad: una perspectiva global". Portal OpenMind. Recuperado en febrero de 2016: https://www.bbvaopenmind.com/articulo/el-impacto-de-interneten-la-sociedad-una-perspectiva-global/?fullscreen =true

"Cómo opera el Gobierno en las redes sociales" (2016). Diario Perfil, 26 de marzo, Buenos Aires, Argentina. Recuperado en febrero de 2016: http://www.perfil.com/politica/como-opera-el-gobiernoen-las-redes-sociales-0326-0052.phtml?utm_source=redir_url_legacy

Derrida, J. (1997), Mal de archivo. Una impresión freudiana. Valladolid, España: Trotta.

. (2013), "Archivo y borrador". En Goldchluk, G. y Pené, M. (compiladoras), Palabras de archivo. Santa Fe: Ediciones UNL-CRLA-Archivos.

Feenberg, A. (2009), "Diez paradojas sobre la tecnología". Conferencia. Traducción de María Carolina Li Gambi. Simon Fraser Universit, Canadá. Recuperado de http://www.sfu.ca/ andrewf/paraspan.pdf

Flores Márquez, D. (2012), "Reflexiones epistemológicas en Desafíos en el estudio de la comunicación en Internet". Virtualis 6, 16-30, agosto-diciembre. Recuperado de http://aplicaciones.ccm.itesm. $\mathrm{mx} / \mathrm{virtualis}$

Fumero, A. (2005), "El abecé del universo blog". En revista Telos 65, octubre-diciembre. Madrid, España.

Gallo, J. (2015), "El primer presidente de Facebook". En diario La Nación, 26 de noviembre. Buenos Aires, Argentina. Recuperado de http://www.lanacion.com.ar/1849036-el-primer-presidente-de-facebook

Glaser, B. G.; Strauss, A. L. (1967), The Discovery of Grounded Theory. New York: Aldine Publishing Company. Traducción de Pablo Alejandro Romero.

Grillo, M. (2008), "La importancia de la definición del campo observacional en las investigaciones sociales: los casos críticos de los estudios de la comunicación y la cultura". Ponencia. I Encuentro Latinoamericano de Metodología de las Ciencias Sociales. Diciembre, La Plata.

Groys, B. (2014), Volverse público. Las transformaciones del arte en el ágora contemporánea. Buenos Aires: Caja Negra Editora.

Hine, C. (2004), Etnografía virtual. Barcelona: UOC.

López, G. y Ciuffoli, C. (2012), Facebook es el mensaje. Oralidad, escritura y después. La Plata: Ed. La Crujía. (2009). Este es el punto a indagar: esto parece ser lo que los mismos diseños buscan generar y neutralizar 
Livingstone, S. (2005). "Critical debates in internet studies: reflections on an emerging field". En Curran, J. y Gurevitch, M. (Eds.), Mass Media and Society (9-28) Londres, UK: Sage. Recuperado de: http:// eprints.lse.ac.uk/1011

Magallanes, L. (2010), Producción y uso del conocimiento en comunidades virtuales. Tesis Doctoral, Facultad de Periodismo y Comunicación Social, Universidad Nacional de La Plata, Argentina.

Manovich, L. (2005), El lenguaje de los medios de comunicación. La imagen en la era digital. Colección Paidós Comunicación. Barcelona: Paidós.

Natanson, J. (2016), "Sobre los emprendedores". En Le Monde Diplomatique Cono Sur, N. ${ }^{\circ} 202$, abril. Recuperado en febrero de 2016 http://www.eldiplo.org//202-el-temblor-brasileno/sobre-losemprendedores

Orihuela, J. L. (2004), "Los weblogs: revolución y consolidación". Revista Chasqui n. 085, marzo. Centro Internacional de Estudios Superiores de Comunicación para América Latina. Quito, Ecuador. Recuperado en febrero de 2016 http://www.revistachasqui.org/index.php/chasqui/article/ view/422/422

Pené, M. (2013), "En busca de una identidad propia para los archivos de literatura". En Goldchluk, G. y Pené, M. (compiladoras), Palabras de archivo. Santa Fe: Ediciones UNL-CRLA-Archivos.

Presidencia de la Nación (2016), "Mauricio Macri se reunió con Sheryl Sandberg, COO de Facebook". República Argentina, publicación oficial Casa Rosada, 21 de enero. Recuperado de http://www. casarosada.gob.ar/informacion/actividad-oficial/9-noticias/35296-mauricio-macri-se-reunio-consheryl-sandberg-coo-de-facebook

Scolari, C. (2008), Hipermediaciones. Elementos para una teoría de la omunicación digital interactiva. Barcelona: Gedisa.

Van Dijck, J. (2016), La cultura de la conectividad. Una historia crítica de las redes sociales. Buenos Aires: Siglo XXI.

Vigna, D. (2014), La década posteada. Blogs de escritores argentinos (2002-2012). Córdoba, Argentina: Centro de Estudios Avanzados-Alción Editora.

Wrede, O. (2005), "Are blogs different to forums?", mayo. Recuperado de http://wrede.interfacedesign. org/archives/992.html 